\title{
B Lymphocytes Limit Senescence-Driven Fibrosis Resolution and Favor Hepatocarcinogenesis in Mouse Liver Injury
}

Francesca Faggioli, ${ }^{1,2}$ Eleonora Palagano, ${ }^{2,3}$ Luca Di Tommaso, ${ }^{4,6}$ Matteo Donadon, ${ }^{5,6}$ Veronica Marrella, ${ }^{1,2}$ Camilla Recordati, ${ }^{7}$ Stefano Mantero, ${ }^{1,2}$ Anna Villa, ${ }^{1,2}$ Paolo Vezzoni, ${ }^{1,2}$ and Barbara Cassani ${ }^{1,2}$

Hepatocellular carcinoma (HCC) is a frequent neoplasia and a leading cause of inflammation-related cancer mortality. Despite that most HCCs arise from persistent inflammatory conditions, pathways linking chronic inflammation to cancer development are still incompletely elucidated. We dissected the role of adaptive immunity in the $\operatorname{Mdr} 2 \operatorname{knockout}\left(M d r 2^{-/-}\right)$ mouse, a model of inflammation-associated cancer, in which ablation of adaptive immunity has been induced genetically (Rag $2^{-/-} M d r 2^{-/-}$and $\mu M t-M d r 2^{-/-}$mice) or with in vivo treatments using lymphocyte-specific depleting antibodies (anti$\mathrm{CD} 20$ or anti-CD4/CD8). We found that activated B and $\mathrm{T}$ lymphocytes, secreting fibrogenic tumor necrosis factor alpha (TNF $\alpha$ ) and other proinflammatory cytokines, infiltrated liver of the $M d r 2^{-/-}$mice during chronic fibrosing cholangitis. Lymphocyte ablation, in the $\operatorname{Rag} 2^{-/-} M d r 2^{-/-}$and $\mu M t-M d r 2^{-/}$mice, strongly suppressed hepatic stellate cell (HSC) activation and extracellular matrix deposition, enhancing HSC transition to cellular senescence. Moreover, lack of lymphocytes changed the intrahepatic metabolic/oxidative state, resulting in skewed macrophage polarization toward an anti-inflammatory M2 phenotype. Remarkably, hepatocarcinogenesis was significantly suppressed in the Rag $2^{-/-} M d r 2^{-/-}$mice, correlating with reduced $\mathrm{TNF} \alpha / \mathrm{NF}-\boldsymbol{\kappa} \mathrm{B}$ (nuclear factor kappa B) pathway activation. Ablation of $\mathrm{CD} 20^{+} \mathrm{B}$ cells, but not of $\mathrm{CD} 4^{+} / \mathrm{CD} 8^{+} \mathrm{T}^{-}$ cells, in $M d r 2^{--}$mice, promoted senescence-mediated fibrosis resolution and inhibited the protumorigenic TNF $\alpha / \mathrm{NF}-\boldsymbol{\kappa} \mathrm{B}$ pathway. Interestingly, presence of infiltrating B cells correlated with increased tumor aggressiveness and reduced disease-free survival in human HCC. Conclusion: Adaptive immunity sustains liver fibrosis (LF) and favors HCC growth in chronic injury, by modulating innate components of inflammation and limiting the extent of HSC senescence. Therapies designed for B-cell targeting may be an effective strategy in LF. (Hepatology 2018;67:1970-1985).

$\mathrm{H}$ epatocellular carcinoma (HCC) is a frequent neoplasia and a leading cause of cancer-related death worldwide. ${ }^{(1)}$ It commonly develops in patients with chronic liver diseases, which may result from viral hepatitis or exposure to metabolic toxins. ${ }^{(1)}$ Chronic hepatic inflammation is a major risk factor for liver tumor development, given that more than $90 \%$ of $\mathrm{HCCs}$ are inflammation driven, ${ }^{(2)}$ thus providing a rationale for the continued development of an immunebased approach to anticancer therapy. ${ }^{(3)}$ Nonetheless, the identification of the cellular actors causing transition from liver cirrhosis to dysplasia and HCC is constantly evolving.

Abbreviations: ALT, alanine aminotransferase; $\alpha S M A, \alpha$-smooth muscle actin; $\beta$-gal, $\beta$-galactosidase; Ccl2, C-C motif chemokine ligand 2; CCN1, cysteine-rich angiogenic inducer 61; CI, confidence interval; Col1a, collagen, type I, alpha; ECM, extracellular matrix; FACS, fluorescence-activated cell sorting; FBS, fetal bovine serum; HCC, hepatocellular carcinoma; HCG, hepatocarcinogenesis; HCV, hepatitis C virus; HF, hepatic fibrosis; HO-1, heme oxygenase-1; HR, hazard ratio; HSCs, hepatic stellate cells; IgG, immunoglobulin G; IL, interleukin; iNOS, inducible NO synthase; LF, liver fibrosis; LPS, lipopolysaccharide; mAb, monoclonal antibody; MHCII, major histocompatibility complex class II; Mmp-13, matrix metalloproteinase13; NOS, NO synthase; NF- $B$, nuclear factor kappa B; NK, natural killer; NKT, natural killer T; NO, nitric oxide; PBS, phosphate-buffered saline; PDGFR- $\beta$, Platelet-derived growth factor receptor- $\beta$; $S A A$, serum amyloid A protein; $S A-\beta$-gal, senescence-associated $\beta$-galactosidase; SASP, senescence-associated secretory phenotype; Tgf $\beta 1$, transforming growth factor beta 1; Timp3, tissue inbibitor of metalloproteinases-3; TIS, therapy-induced senescence; TLR4, Toll-like receptor 4; TNFa, tumor necrosis factor alpha; TUNEL, terminal deoxynucleotidyl transferase dUTP nick end labeling; wt, wild type.

Received May 16, 2017; accepted October 31, 2017

Additional Supporting Information may be found at onlinelibrary. wiley.com/doi/10.1002/hep.29636/suppinfo. 
Innate immune cells indisputably play a key role in fibrosis initiation and progression, and the occurrence of tumor-associated macrophages has been linked to immune suppression, angiogenesis, and tumor progression. ${ }^{(4)}$ However, adaptive immunity also has a fundamental impact on the development and progression of HCC, eliciting both antitumor and protumor effects. $^{(5-8)}$ In addition, the regulation of cellular senescence, a process that opposes tumor initiation and progression, is also influenced by $\mathrm{T}$-cell function. In fact, $\mathrm{CD}^{+} \mathrm{T}$ lymphocytes can either induce growth arrest and senescence in cancer cells by secreting proinflammatory cytokines or trigger the clearance of senescent premalignant hepatocytes. ${ }^{(9-11)}$

Interestingly, a role for B cells in the pathogenesis of liver fibrosis (LF) has been also hypothesized. ${ }^{(12)}$ To unravel the role of adaptive immune responses in the pathogenesis of HCC, we utilized the Mdr2 knockout mice $\left(M d r 2^{-/}\right)$mouse model lacking the liver-specific P-glycoprotein, responsible for phosphatidylcholine transport across the canalicular membrane. ${ }^{(13)}$ The absence of phospholipids from bile leads to bile regurgitation into the portal tracts, causing important portal inflammation followed by slowly developing HCC, which closely mimics the human disease. ${ }^{(14)}$ Thus, this model is very suitable for investigating the role of adaptive immunity in chronic inflammation during premalignancy, senescence immune surveillance, and cancer.

\section{Materials and Methods}

\section{MICE AND TREATMENTS}

\author{
C57BL6/J-Abcb4 ${ }^{\mathrm{tm} 1 \mathrm{Bor}} \quad\left(M d r 2^{-/-}\right), \quad$ B6.129S2-
}

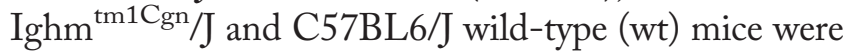
from The Jackson Laboratory (USA). B6.129S6Rag $2^{\text {tm1FWA }}$ N12 mice were purchased from Taconic (USA). Mice were bred and housed under specific pathogen-free conditions at the Animal Facility of the Humanitas Clinical and Research Center in compliance with national and international law and policies. Food and water were provided ad libitum. To deplete $\mathrm{CD}_{20}{ }^{+}$B lymphocytes, 5-month-old male mice were treated once every 2 weeks with intravenous injections of anti-mouse CD20 monoclonal antibody (mAb; clone 18B12, $7.5 \mu \mathrm{g} / \mathrm{g}$ of body weight; Biogen) for 8 weeks. To deplete $\mathrm{CD} 4^{+} \mathrm{T}$ and $\mathrm{CD} 8^{+} \mathrm{T}$ cells, mice were subjected to intravenous injections of Rat anti-mouse CD4 and anti-mouse CD8a mAbs (clones GK1.5 and 53-6.7; BioXcell, West Lebanon, USA). CD4- and CD8-depleting antibodies were administered every 7 days at doses of $7.5 \mu \mathrm{g} / \mathrm{g}$ of body weight, for 8 weeks. Control groups received the corresponding isotype controls (immunoglobulin $\mathrm{G}[\mathrm{IgG}] 1$, IgG2a, and IgG2b; BioXcell). Animals were sacrificed for analysis 1 week after the last injection. Experiments were performed according to protocols approved by the

Supported by grants MIUR-FIR RBFR12I3UB (to B.C.), MIUR-FIRB RBAP11H2R9-004 (to P.V.), AMANDA Project (Regione Lombardia/CNR) to P.V., and CNR-DSB Aging Project (to P.V) and Prot. No. 0059711 (to F.F.).

Copyright $(0) 2017$ by the American Association for the Study of Liver Diseases.

View this article online at wileyonlinelibrary.com.

DOI 10.1002/hep.29636

Potential conflict of interest: Nothing to report.

\section{ARTICLE INFORMATION:}

From the ${ }^{1}$ Milan Unit, Istituto di Ricerca Genetica e Biomedica, National Research Council, Milan, Italy; ${ }^{2}$ Humanitas Clinical and Research Center, Rozzano, Italy; ${ }^{3}$ Department of Medical Biotechnologies and Translational Medicine, University of Milan, Milan, Italy; ${ }^{4}$ Pathology Unit and ${ }^{5}$ Department of Hepatobiliary and General Surgery, Humanitas Clinical and Research Center, Rozzano, Italy; ${ }^{6}$ Department of Biomedical Sciences, Humanitas University, Rozzano, Italy; and ${ }^{7}$ Mouse and Animal Pathology Laboratory, Fondazione Filarete, Milano, Italy.

\section{ADDRESS CORRESPONDENCE AND REPRINT REQUESTS TO:}

Barbara Cassani, Ph.D.

Milan Unit, Istituto di Ricerca Genetica e Biomedica,

National Research Council (CNR)

via Manzoni 113

20089, Rozzano, Italy

E-mail: barbara.cassani@humanitasresearch.it

Tel: +39-02-82245153; or
Francesca Faggioli, Ph.D.

Milan Unit, Istituto di Ricerca Genetica e Biomedica,

National Research Council (CNR)

via Manzoni 113

20089, Rozzano, Italy

E-mail: francesca.faggioli@humanitasresearch.it

Tel: +39-02-82245153 
Istituto Clinico Humanitas and the Italian Institutional Animal Care and Use Committee.

\section{LIVER LYMPHOCYTE ISOLATION}

Mice were euthanized by $\mathrm{CO}_{2}$ inhalation. The hepatic portal vein was cannulated and perfused with 10 $\mathrm{mL}$ of ice-cold phosphate-buffered saline (PBS). After the removal of the gall bladder, the liver was rinsed with ice-cold PBS, chopped on ice into small $\sim 1-\mathrm{mm}^{3}$ pieces, and then enzymatically digested in Iscove's modified Dulbecco's medium medium supplemented with $0.2 \mathrm{mg} / \mathrm{mL}$ of Liberase TL (Sigma-Aldrich, NJ, USA) and $0.01 \mathrm{mg} / \mathrm{mL}$ of DNase I (Sigma-Aldrich) for 30 minutes at $37^{\circ} \mathrm{C}$. The enzymatic reaction was stopped using ethylenediaminetetraacetic acid $(5 \mathrm{mM})$, and the liver suspension was meshed through a $70-\mu \mathrm{m}$ cell strainer (Falcon, Tewksbury MA, USA). After centrifugation, the cell pellet was resuspended in $40 \%$ Percoll solution (92\% Percoll, 7\% PBS $10 \times$, and $1 \% \mathrm{NaHCO}_{3}$ 7.2\%; pH 7.2) in Hank's balanced salt solution supplemented with $100 \mathrm{UI} / \mathrm{mL}$ of heparin. After a centrifugation $\left(1,800 \mathrm{rpm}, 20\right.$ minutes, $\left.4^{\circ} \mathrm{C}\right)$, the pellet was harvested and resuspended in RPMI 1640 medium with $5 \%$ fetal bovine serum (FBS).

\section{IN VITRO CULTURE}

Sorted liver $\mathrm{CD} 19^{+} \mathrm{B} 220^{+} \mathrm{B}$ and $\mathrm{CD} 3^{+} \mathrm{NK} 1.1^{-} \mathrm{T}$ cells were resuspended at $2 \times 10^{5}$ cells $/ \mu \mathrm{L}$ in $\mathrm{RPMI}$ $1640,10 \% \mathrm{FBS}$, and $2 \mathrm{mM}$ of L-glutamine and transferred into a flat-bottomed 96-well plate in $100 \mu \mathrm{L} /$ well. Another $100 \mu \mathrm{L}$ of RPMI was added that contained or not stimulating reagents at $2 \times$ final concentration. In case of in vitro liver T-cell stimulation, plates were previously coated with anti-mouse CD3 antibody $(2 \mu \mathrm{g} / \mathrm{mL}$, clone $145-2 \mathrm{C} 11$; eBioscience, MA, USA) for 3 hours at $37^{\circ} \mathrm{C}$. Liver $\mathrm{B}$ cells were stimulated with lipopolysaccharide (LPS; $10 \mu \mathrm{g} / \mathrm{mL}$; Sigma-Aldrich). Cocultures between liver B cells and splenic wt $\mathrm{T}$ cells were performed in the presence of soluble anti-mouse CD3 antibody $(2 \mu \mathrm{g} / \mathrm{mL}$; eBioscience). Supernatants were collected after 3 ( $\mathrm{T}$ cells) or 5 days (B cells) of culture for cytokine secretion determination, and then cell proliferation was evaluated by ${ }^{3} \mathrm{H}$-thymidine incorporation. In vitro cocultures with hepatic stellate cells (HSCs) were established in normal or $5-\mu \mathrm{M}$ pore-size Transwell inserts (Costar Corporation, Corning, NY, USA) 24well plates, at a ratio 1:10 (HSC:T/B cells).
Supernatants and HSCs for gene expression analysis were harvested after 5 days of culture.

\section{HUMAN SAMPLES}

A tissue microarray composed of 116 samples of HCC was obtained from the Department of Hepatobiliary and General Surgery of Humanitas Clinical and Research Center with the approval of the institutional review board (Prot. No. CE Humanitas ex D.M. 8/2/ 2013-248/14) and after the patient's informed consent. All patients had hepatitis $\mathrm{C}$ virus ( $\mathrm{HCV}$ )-related cirrhosis. The series under examination is enriched by complete clinical, pathological, and phenotypical data. ${ }^{(15)}$ Each case was represented by six tumoral spots, three taken from inner and three from outer HCC areas, and three extratumoral spots. CD20 expression was semiquantitatively evaluated in each spot and expressed as the mean percentage of immunoreactive cells in the tissue for each case. The histological tumor grading was evaluated in accord with Broder's classification.

\section{IMMUNOHISTOCHEMISTRY}

Livers were systematically set up following the practice guideline suggested by Fickert et al. ${ }^{(16)}$ Paraffinembedded tissue sections were stained for terminal deoxynucleotidyl transferase dUTP nick end labeling (TUNEL; Calbiochem) and with the following antibodies: ki67 (clone D3B5, 1:400; Cell Signaling Technology); $\alpha$-smooth muscle actin ( $\alpha$ SMA; RB 9010-P1, 1:100; Thermo Fisher Scientific); $\gamma$ H2A.X (clone 9718, 1:100; Cell Signaling Technology, MA, USA); CD3 (MCA1477, 1:1,000: Bio-Rad Laboratories); Ym1 (1:400, no. 01404; Stem Cell Technologies, Vancouver, Canada); major histocompatibility complex class II (MHCII; 1:150, ab25333; Abcam, Cambridge, UK); heme oxygenase 1 (HO-1; 4915-1050, 1:400; Bio-Rad Laboratories); CD45R (BMS14-0452-82, 1:400; eBioscience); and anti-CD20 L26 (760-2531, Ventana, AZ, USA). One whole section from each animal (at least eight for each group) was scanned with vs-120dot-slide. The images were quantified using Image Pro-premier software (http://rsb.info.nih.gov/ij/). The immunereactive area was calculated relative to the total liver section area. Detection of $\beta$-galactosidase $(\beta$-gal) activity was performed with the Senescence Detection kit (BioVision, CA, USA) on snap-frozen livers, following the manufacturing instruction. Microscopic analysis was performed using an Olympus BX51 (Olympus Corporation). Five high-power fields were counted on two 
liver sections from each mouse $(20 \times$ or $40 \times,>150$ counted cells per field).

\section{STATISTICAL ANALYSIS}

All statistical analyses were performed using the Mann-Whitney U or Student $t$ test. For histopathology, data extrapolated using Image Pro-premier software were analyzed with GraphPad Prism (version 7.0; GraphPad Software Inc., San Diego, CA). Statistical analyses of the results were performed using the Kruskal-Wallis test, followed by Dunn's test. $P$ values $<0.05$ were considered statistically significant.

For human studies, data are expressed as means \pm SD. Variables were compared using the chi-square test (or Fisher's exact test) for categorical data and Student $t$ test (or the Mann-Whitney U test) for continuous variables. Kaplan-Meier curves were used to analyze differences of overall and disease-free survivals that were compared using the log-rank test. Proportional hazard/Cox regression analysis was used to identify independent prognostic factors. Hazard ratio (HR) with confidence interval $(\mathrm{CI})$ was used as effect size. A $P$ value $<0.05$ was considered significant. All tests were two-sided. All analyses were performed with the software Stata 13 (StataCorp LP).

\section{Results}

\section{INTRAPORTAL ACCUMULATION OF LYMPHOCYTES IN INJURED LIVER OF $M d r 2^{-/}$MICE}

To investigate the contribution of the adaptive immune cells in the inflammatory responses linked to HCC development, we evaluated the hepatic immune microenvironment of $\mathrm{Mdr}^{-/-}$mice at the stage of chronic hepatitis. At the age of 7 months, mutant livers showed a prominent periportal ductular proliferation accompanied by leukocyte infiltration (Fig. 1A). Flow cytometry analysis on liver single-cell suspensions revealed markedly increased frequencies of $\mathrm{CD}^{+}{ }^{+} \mathrm{T}$ cells and $\mathrm{B} 220^{+} \mathrm{CD} 19^{+} \mathrm{B}$ cells in the $\mathrm{CD} 45^{+}$fraction of mutant liver cells with respect to controls (Fig. 1B). No significant alterations were detected for natural killer $\mathrm{T}$ $\left(\mathrm{NKT} ; \mathrm{CD}^{+}{ }^{+} \mathrm{NK} 1.1^{+}\right)$and natural killer (NK; CD3 ${ }^{-}$ NK1. $1^{+}$) subsets (Supporting Fig. S1A). Importantly, Band $\mathrm{T}$-cell infiltrates were localized predominantly at the periportal areas, where tissue injury arose (Fig. 1A), suggesting a primary involvement in the liver disease. To elaborate the role of lymphocytes in our model, we isolated, by fluorescence-activated cell sorting (FACS), intrahepatic $\mathrm{CD} 19^{+} \mathrm{B}$ - and $\mathrm{CD}^{+}$T-cell populations from perfused livers of $M d r 2^{-/}$and wt mice. Liver mutant B cells were in an increased activation state, characterized by enhanced expression of activation and costimulatory markers, such as MHCII, CD86, and CD40 (Fig. 1C and Supporting Fig. S1B). Consistent with their phenotype, $M d r 2^{-/-} \mathrm{B}$ cells exhibited higher ability to prime and activate wt $\mathrm{T}$ cells in vitro (Supporting Fig. S1C,D). Likewise, T lymphocytes from mutants displayed greater levels of CD44, CD25, and CD69 markers compared to their normal counterpart (Fig. 1C and Supporting Fig. S1B). Next, we analyzed liver Band $\mathrm{T}$-cell functions following ex vivo stimulation with LPS and anti-CD3 mAb, respectively. Liver lymphocytes from $M d r 2^{--}$mice displayed increased proliferative ability and produced greater amounts of the tumor necrosis factor alpha (TNF $\alpha$ ) cytokine compared to controls (Fig. 1D,E). Thus, immune activity of $\mathrm{B}$ and $\mathrm{T}$ cells is enhanced during the pretumoral stage.

\section{ABSENCE OF ADAPTIVE IMMUNITY REDUCES COLLAGEN DEPOSITION AND HSC ACTIVATION}

The functional role of adaptive immunity in HCC pathogenesis was investigated utilizing $\operatorname{Rag} 2^{-1-} M d r 2^{-1-}$ mice, which lack mature T and B cells. ${ }^{(17)}$ Liver histological examination confirmed that 7-month-old $M d r 2^{-1}$ mice were affected by overt hepatic fibrosis $(\mathrm{HF})$, characterized by marked portal to bridging oval cell/biliary hyperplasia, extracellular collagen deposition, and inflammatory reactions (Fig. 2A). As quantified by laser scanning, we found a rate of $2.6 \pm 1.4 \%$ of Picrosirius redpositive collagen fibers in $M d r 2^{-/-}$mice, representing a 12 -fold increase over controls $(0.2 \pm 0.19 \%)$. Furthermore, a dramatic expansion of activated HSCs, positive for the marker, $\alpha \mathrm{SMA}$, was also observed in the mutant compared to WT mice $(6 \pm 2.2 \%$ vs. $0.8 \pm 0.5 \%$; Fig. 2B). Remarkably, collagen deposition, oval cell/biliary hyperplasia, and inflammatory cell infiltration were visibly reduced in liver of age-matched $\mathrm{Rag} 2^{-1-} \mathrm{Mdr} 2^{-/-}$mice (now referred as Dko), as demonstrated by the lower relative organ weight and histological score (Fig. 2C,D). Smaller $\alpha \mathrm{SMA}^{+}$areas and fewer collagen fibrils reflected a $50 \%$ reduction in HSC activation and collagen deposition in Dko mice ( $3 \pm 1.2 \%$; Fig. $2 \mathrm{~A}, \mathrm{~B})$. Consistently, liver mRNA expression of fibrogenic markers, including Col1a1, collagen, type I, alpha 1 (Col1a)1, Col1a2, and transforming growth factor beta 1 (Tgf $\beta 1)$, were 
A

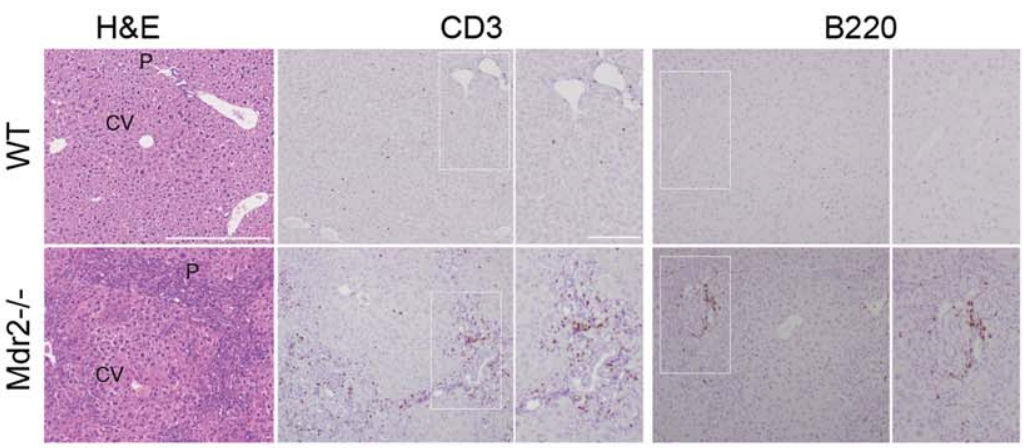

B
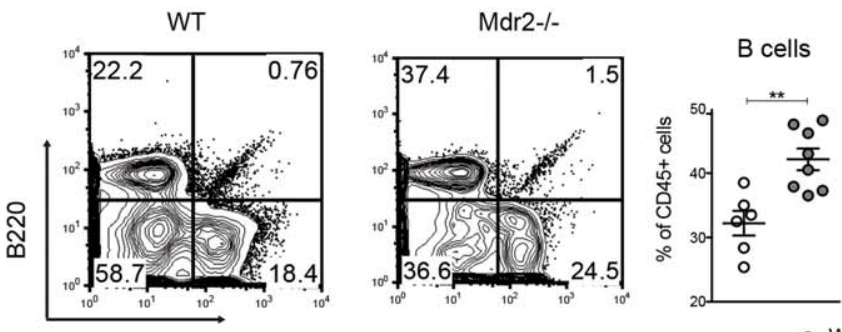

CD3 T cells

CD3

० WT OMdr2-1

C
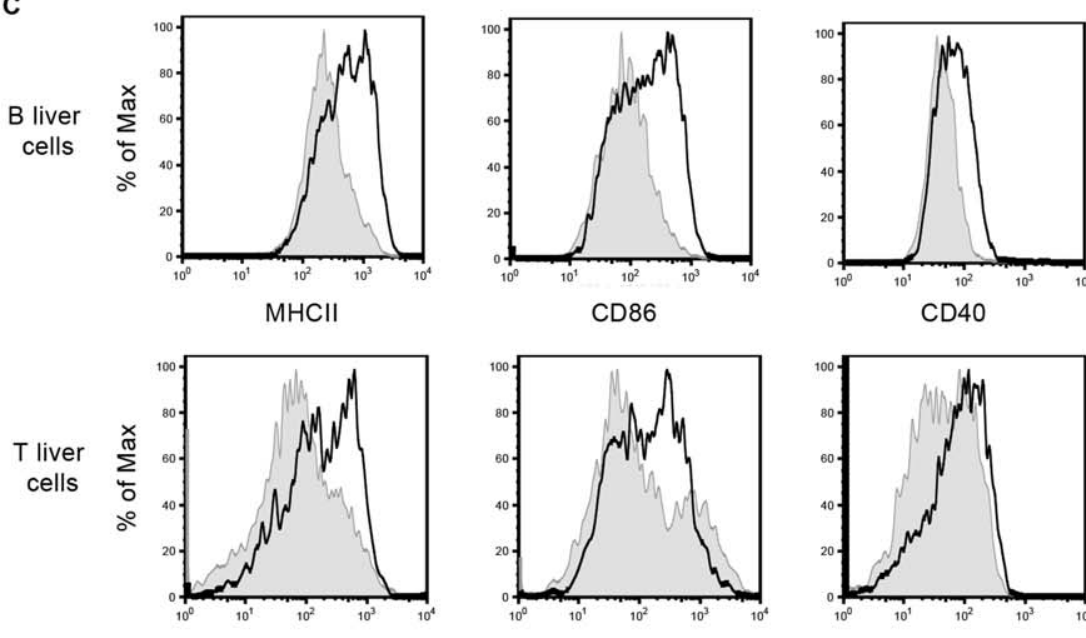

CD44
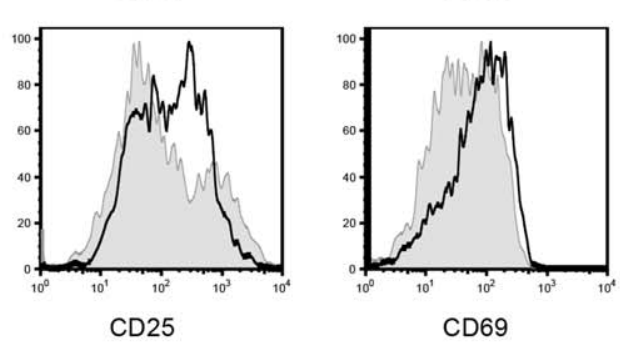

- WT

- Mdr2-/-

D

B liver cells

T liver cells

E
CD69
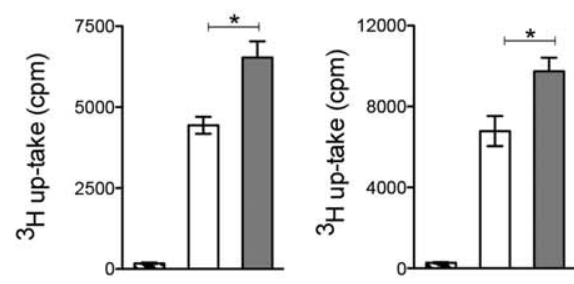

$\mathrm{TNF} \alpha$

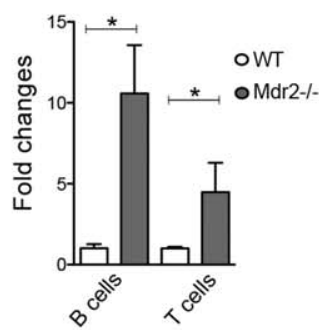

not stimulated oWT stimulated

- Mdr2-/-stimulated

FIG. 1. Intraportal accumulation of lymphocytes in injured liver of $M d r 2^{-/-}$mice. (A) Representative images from H\&E, CD3, and B220 staining on liver sections of wt and $M d r 2^{-/-}$mice. Scale bar $=250 \mu \mathrm{m}$. (B) Representative dot plots depicting expression of B220 and CD3 markers on gated $\mathrm{CD}_{4} 5^{+}$liver cells from wt and $M d r 2^{-/-}$mice. Numbers in quadrants indicate percentage of cells in each. Graphs show cumulative frequencies from two representative experiments of five independent with $n=6-8$ mice/group. (C) Representative FACS plots showing expression of activation markers, on gated CD19 ${ }^{+} \mathrm{B}$ cells and CD3 ${ }^{+} \mathrm{T}$ cells from liver of wt and $M d r 2^{-/}$mice. (D) Liver CD19 $9^{+} \mathrm{B}$ cells and $\mathrm{CD}^{+} \mathrm{T}$ cells were sorted from wt and $M d r 2^{-/-}$mice and stimulated ex vivo with LPS and anti-CD3 mAb, respectively. Lymphocyte proliferation was evaluated after 96 hours of culture by ${ }^{3} \mathrm{H}$-thymidine incorporation. (E) Cytokine secretion in culture supernatants was evaluated by ELISA. Values are mean \pm SEM. ${ }^{*} P<0.05$. Abbreviations: cpm, counts per minute; CV, central vein; ELISA, enzyme-linked immunosorbent assay; H\&E, hematoxylin and eosin; Max, maximum; P, portal tract. 

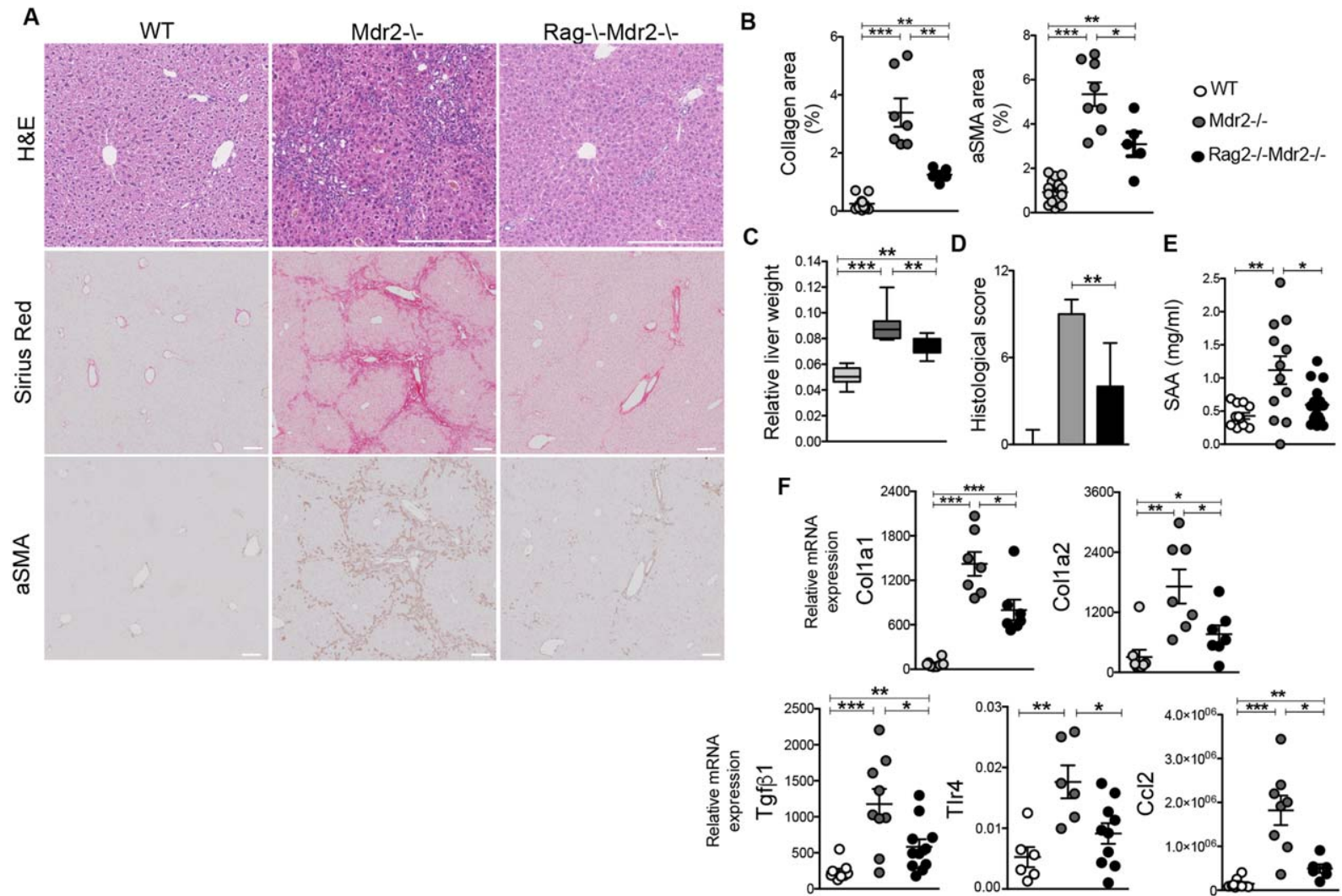

FIG. 2. Reduced collagen deposition and HSC activation in the absence of adaptive immunity. (A) Representative images from H\&E, Sirius Red, and $\alpha$ SMA stainings on liver sections of wt, $M d r 2^{-/}$, and Dko mice. Scale bar $=250 \mu \mathrm{m}$. (B) Quantification of Sirius Red and $\alpha$ SMA-positive areas in livers of mutants and age-matched control mice. (C) Relative liver weight is shown. (D) Histological score was evaluated considering inflammatory infiltrates, fibrosis, biliary, and oval cell hyperplasia. Experimental data are cumulative results from independent experiments with at least 7 mice/group. Values are median \pm range. (E) Serum SAA levels were measured at the preneoplastic stage (7 months). (F) Quantitative analysis of profibrogenic factors Col1a1, Col1a2, Tgf $\beta$, Tlr4, and $\mathrm{Ccl} 2$ was performed by qRT-PCR on whole-liver tissue. Data are representative results of two independent experiments with at least 6 mice/group. Values are mean \pm SEM. ${ }^{*} P<0.05$; ${ }^{* *} P<0.01$; ${ }^{* * *} P<0.001$. Abbreviation: H\&E, hematoxylin and eosin.

significantly reduced (Fig. 2F). Decreased hepatic inflammation in Dko was also confirmed by reduced serum levels of serum amyloid A (SAA) protein (Fig. 2E). Tolllike receptor 4 (TLR4) is required for hepatic fibrogenesis, driving HSC activation and enhancing their sensitization to TGF $\beta$ signaling. ${ }^{(18)}$ In line with the downregulation of Tgf $\beta 1$ expression, liver Tlr 4 mRNA was significantly reduced in Dko, compared to $M d r 2^{-/}$, mice (Fig. 2F). Additionally, expression of $\mathrm{C}-\mathrm{C}$ motif chemokine ligand 2 ( $C c l 2)$, a potent mediator of macrophage recruitment and linked to TLR4 activation, ${ }^{(18)}$ was also decreased (Fig. 2F). To corroborate the role of lymphocytes in HSC activation and fibrosis, we performed cocultures of ex vivo purified $M d r 2^{-1-} \mathrm{B}$ and T cells with wt HSCs. We confirmed that $M d r 2^{-/-}$lymphocytes produce a high amount of Tnf $\alpha$ as well as of interleukin (IL) 6 and IL1 $\beta$ (Supporting Fig. S2A). Furthermore, we found that B cells isolated from $M d r 2^{--}$mice are more potent stimulators of HSC activation, measured by $I L 1 \alpha, C c l 2$, Lox, and Col1a2 mRNA levels, when they are in direct cell-to-cell contact rather than separated in transwell cultures (Supporting Fig. S2B).

Overall, these data suggest that lymphocytes regulate the pathways sustaining HF following chronic liver injury.

\section{ADAPTIVE IMMUNITY PROMOTES THE INFLAMMATORY PROTUMORIGENIC MICROENVIRONMENT OF FIBROTIC $M d r 2^{-/}$LIVERS}

$\mathrm{TNF} \alpha / \mathrm{NF}-\kappa \mathrm{B}$ signaling promotes disease progression and HCC development in $M d r 2^{-/-}$mice. ${ }^{(6)}$ 
Accordingly, cholangiohepatitis in 7-month-old $M d r 2^{-/}$mice was characterized by markedly increased liver mRNA and serum concentration of Tnf $\alpha$ (Fig. 3B), correlating with augmented hepatic activation of the NF- $\kappa \mathrm{B}$ pathway, as demonstrated by the higher p65 phosphorylation in western blotting analysis (Fig. $3 \mathrm{C})$. In contrast, the $\mathrm{TNF} \alpha / \mathrm{NF}-\kappa \mathrm{B}$ axis was suppressed in age-matched Dko mice (Fig. 3A-C), confirming that adaptive immune responses significantly contributed to the activation of this inflammatory signaling pathway.

During the inflammatory phase of chronic wounds, $\mathrm{TNF} \alpha$, in combination with other factors, induces the synthesis of nitric oxide (NO), which contributes to liver fibrogenesis. ${ }^{(19)}$ In agreement, a marked increase in the inducible NO synthase (iNOS) Nos2 transcript level was detected in hepatic tissue of $\mathrm{Mdr}^{-/}$mice (Fig. 3D). In Dko mice, inos expression was significantly inhibited, resulting in higher Arginase I activity (Fig. 3D). Increased Arginase I in Dko mice likely reflected reduced liver damage, compared to $M d r 2^{-/-}$ mice. It was also noteworthy that blunted $T N F \alpha-$ induced up-regulation of inos in Dko mice correlated with significantly increased antioxidant $\mathrm{HO}-1 \mathrm{immu}-$ noreactivity (Fig. 3E,F, upper panel).

Arginine metabolism by NO synthase (NOS) or Arginase has profound consequences on macrophage polarization. ${ }^{(20)}$ We examined the macrophage phenotype in $M d r 2^{-/}$and Dko mice. Inflammatory M1type macrophages are abundantly present in liver of $M d r 2^{-/}$, compared to wt mice, as demonstrated with MHCII immunostaining (Fig. 3E,F, middle panel). In contrast, M1 macrophage polarization was significantly suppressed in Dko mice in favor of a skewing toward anti-inflammatory M2-differentiated macrophages, as confirmed by the higher liver immunoreactivity for the Ym1 marker (Fig. 3E,F, bottom panel). Thus, adaptive immunity is critical to maintain the inflamed hepatic environment and to dictate macrophage polarization driving fibrosis progression.

\section{CYSTEINE-RICH ANGIOGENIC INDUCER 61-DRIVEN SENESCENCE PROGRAM IS ENHANCED IN $\mathrm{Rag}^{-/-} \mathrm{Mdr}^{-/-} \mathrm{MICE}$}

Cellular senescence plays a key role in restoring tissue homeostasis after liver injury, by limiting the proliferation of activated HSCs and hence the extent of extracellular matrix (ECM). ${ }^{(21)}$
Therefore we asked whether dampen of fibrosis in the Dko mice could be ascribed to cellular senescence activation. To identify senescent cells in situ, we stained liver sections for senescence-associated markers, Ki-67 and SA- $\beta$-gal. Immunohistochemistry for $\mathrm{Ki}-67$ revealed that $M d r 2^{-/-}$livers contained nearly 2-fold more proliferating cells compared with control and Dko mice (Fig. 4A,B). In addition, senescenceassociated $\beta$-galactosidase (SA- $\beta$-gal)-positive cells accumulated at a relatively low frequency in fibrotic $M d r 2^{-/}$livers, almost comparable to that of wt controls (Fig. 4A,B). On the contrary, a marked accumulation of $\mathrm{SA}-\beta$-gal ${ }^{+}$cells was observed in the portal and periportal areas of Dko liver (Fig. 4A). The reduced expression of platelet-derived growth factor receptor- $\beta$ (Pdgfr $\beta)$, a feature of myofibroblast activation, in livers of Dko mice (Fig. $4 \mathrm{C}$ ) would suggest that $\mathrm{SA}-\beta$-gal ${ }^{+}$senescent cells are most likely derived from activated HSCs, which reverted or stalled to a less-reactive phenotype. Accordingly, in serial sections of Dko livers, most of the $\beta$-gal-positive cells also express $\alpha$ SMA marker (Fig. 4D). To further confirm this finding, HSCs were isolated from livers and cultured for 6 days. Purity of HSC cultures was assessed by endogenous retinoid fluorescence and oil red staining, marking cytoplasmic lipid droplets typically of HSCs (Supporting Fig. S3A,B). Accordingly, SA- $\beta$ $\mathrm{gal}^{+}$senescent Dko HSCs secreted large amounts of inflammatory senescence-associated secretory phenotype (SASP) factors, including IL6, Ccl2, IL1 $\alpha$, and granulocyte macrophage/colony-stimulating factor (Supporting Fig. S3E). Interestingly, no production of TNF $\alpha$ was detected (data not shown).

In liver injury, the hepatocyte-derived matricellular protein, CCN1, is critical for induction of HSC senescence, through a RAC/NADPH oxidase 1-dependent pathway. ${ }^{(22)}$ A significant increase in $\mathrm{Ccn} 1$ tissue expression was observed in Dko, compared to $M d r 2^{-/}$, mice (Fig. 4E). Importantly, enhanced Ccn1 expression correlated with increased Rac1 transcript level in purified HSCs from Dko, with respect to $M d r 2^{-/}$, mice (Supporting Fig. S3C). Up-regulation of $\mathrm{C} c n 1$ has been linked to apoptosis. ${ }^{(23)}$ However, the presence of fewer scattered apoptotic hepatic cells, identified by TUNEL staining in Dko mice with respect to $M d r 2^{-/}$, confirmed that cellular senescence is the principal mechanism of restrained LF (Fig. 4F).

Finally, we examined livers for markers of extracellular proteolysis, related to wound resolution. Expression of collagenase 3 (matrix metalloproteinase-13; $M m p$ 13) diminished in Dko livers compared to the $M d r 2^{-/-}$ 
A

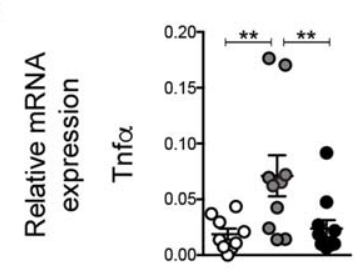

B

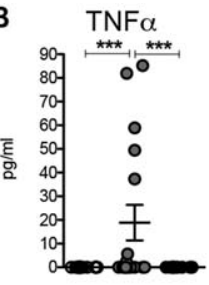

C

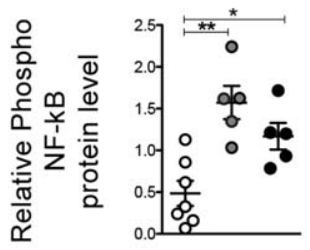

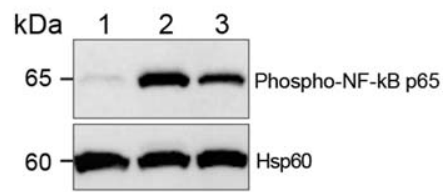

D

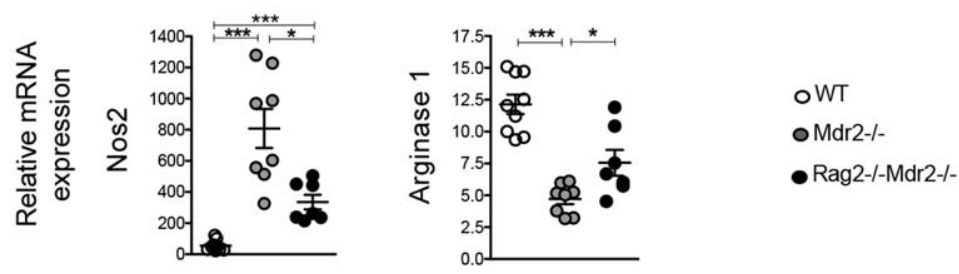

E

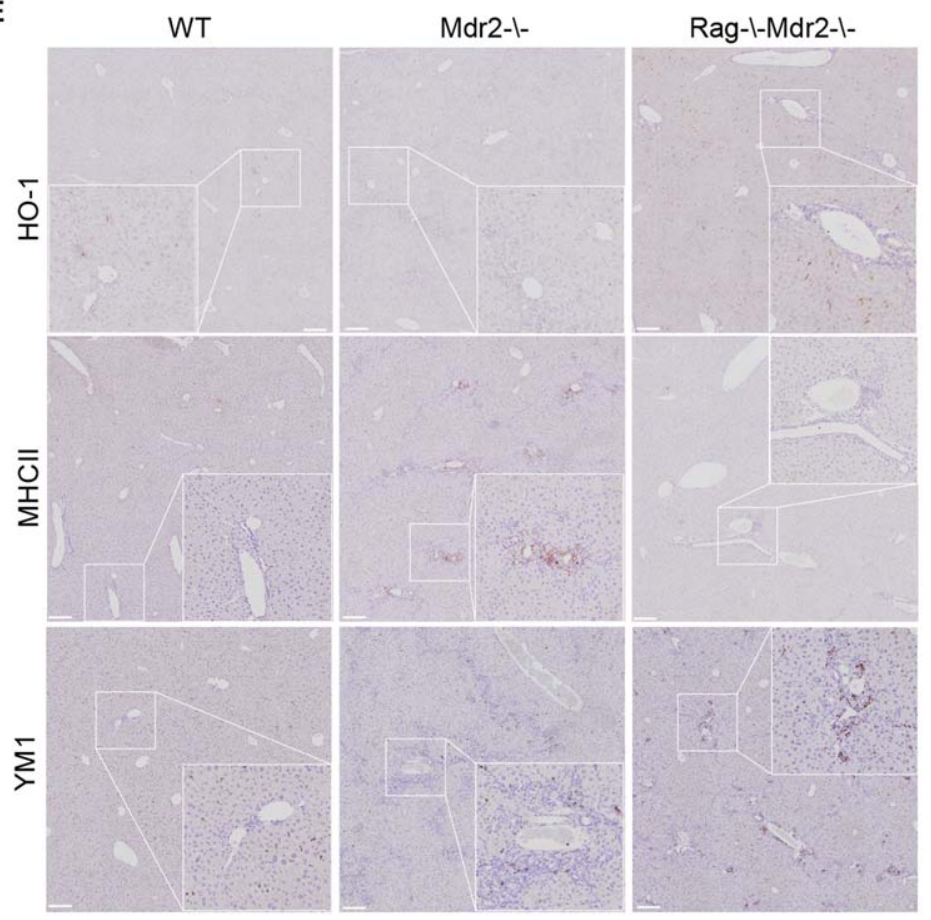

F
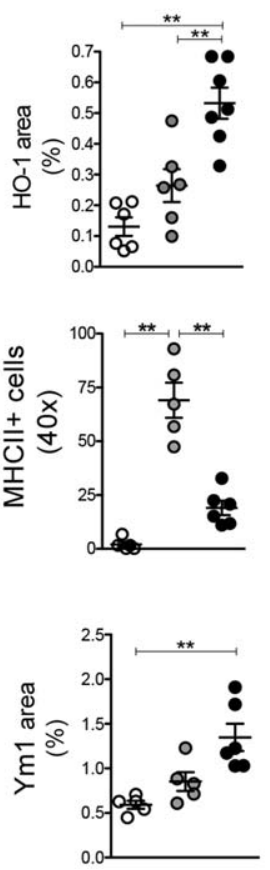

FIG. 3. Reduced hepatic TNF $\alpha$ inflammation and switched macrophage polarization in the absence of lymphocytes. (A-D) mRNA and (C) proteins from total liver tissue were isolated from wt, $M d r 2^{-\prime-}$, and Dko mice at 7 months. (A,D) Quantitative analysis of Tnf $\alpha$, Nos2, and Arginase 1 was performed by qRT-PCR. Data shown are cumulative results from two independent experiments with at least 7 mice/group. (B) TNF $\alpha$ serum levels are shown. (C) Representative immunoblotting showing expression of phospho-NF- $\kappa \mathrm{B} /$ p65 in livers of mutants and wt mice. Quantification of phospho-NF- $\kappa \mathrm{B} / \mathrm{p} 65$ relative to Hsp-60 protein level. Samples: $1=$ wild type; $2=M d r 2^{-1-} ; 3=$ Dko. (E) Representative images and (F) quantification of immunoreactivity for HO-1, MHCII, and Ym1 on liver sections. Scale bar $=200 \mu \mathrm{m}$; scale bar inset $=67 \mu \mathrm{m}$. Data are represented as a mean \pm SEM. ${ }^{*} P<0.05 ;{ }^{* *} P<0.01$. Abbreviation: Hsp-60, heat shock protein 60.

mouse (Fig. 4E), indicative of an overall protective effect against fibrosis. ${ }^{(24)}$ Furthermore, mRNA levels of tissue inhibitor of metalloproteinases-3 (Timp3) profibrotic gene, encoding for metalloproteinases inhibitor, were also down-regulated in the Dko mouse (Fig. 4E). These results suggest a major role for adaptive immunity in the perpetuation, rather than resolution, of cholangiohepatitis. 
A
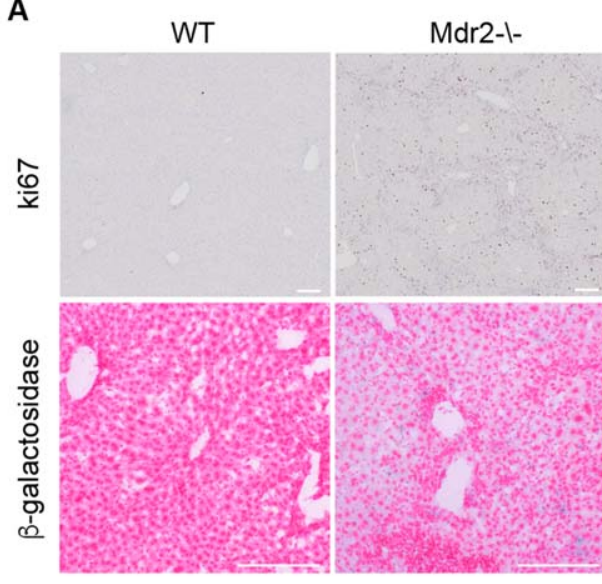

D

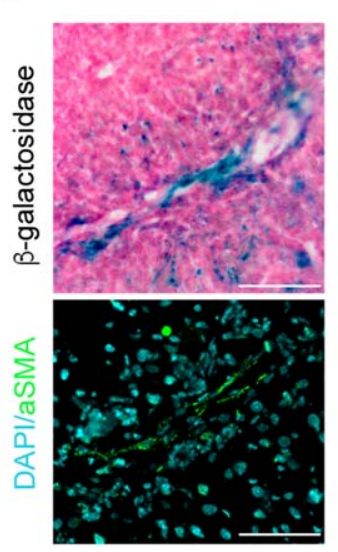

E

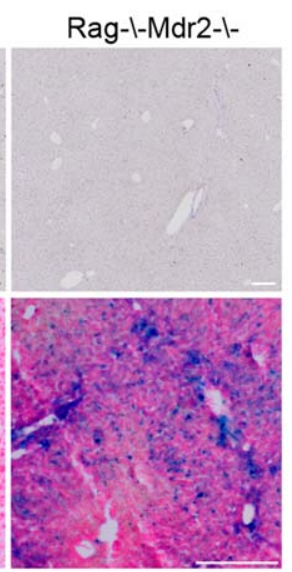

B
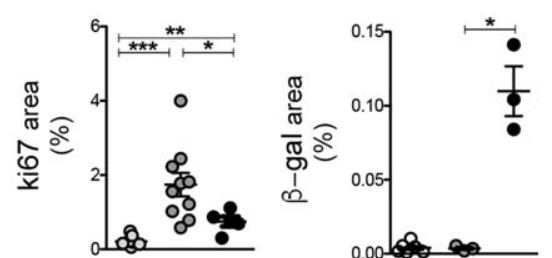

C

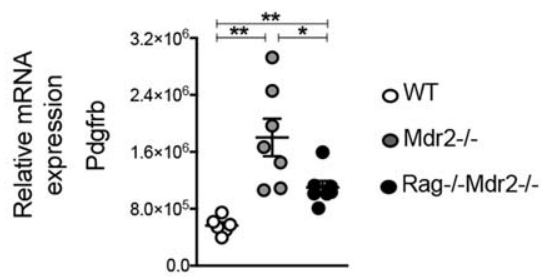

FIG. 4. Enhanced senescence of HSC in $R a g 2^{--} M d r 2^{-\alpha}$ mice. (A) Liver tissues were stained for Ki-67 antibody (top) and processed for $\beta$-gal staining (bottom). Scale bar $=250 \mu \mathrm{m}$ (top panel) and $200 \mu \mathrm{m}$ (bottom panel). (B) Quantification of Ki-67- and $\beta$-galpositive areas in mutants and control livers. (C, E) RNA from total liver was isolated from wt, $M d r 2^{-/}$, and Dko mice at 7 months to perform qRT-PCR for Pdgfr- $\beta$, Ccn1, Mmp3, and Timp3. (D) Senescent cells, identified by SA- $\beta$-gal, stained positive for HSC marker $\alpha$ SMA on serial sections of Dko liver. Scale bar $=100 \mu \mathrm{m}$. (E) qRT-PCR analysis of wound-healing resolution markers Ccn1, Mmp3, and Timp3, in livers of wt, $M d r 2^{-/}$, and Dko mice. (F) TUNEL staining on liver sections were taken and quantified. Scale bar $=100 \mu \mathrm{m}$. Data are represented as mean \pm SEM. ${ }^{*} P<0.05 ;{ }^{* *} P<0.01$. Abbreviation: DAPI, 4 ,, 6 -diamidino-2-phenylindole.

\section{B LYMPHOCYTES ARE SUFFICIENT FOR THE ESTABLISHMENT OF HF}

To dissect the relative contribution of $\mathrm{B}$ and $\mathrm{T}$ cells in hepatitis, we treated $M d r 2^{-/-}$mice with lineage-specific depleting antibodies (anti-CD20 or anti-CD4/CD8, now referred to as B-Mdr2 $2^{-/}$and $\mathrm{T}-M d r 2^{-/}$) intravenously for 2 months, starting from 5 months of age. Administration of antiCD20 mAb efficiently produced B-cell depletion in peripheral blood and liver of mutant mice (Supporting Fig. S4A,B). Similarly to Dko mice, collagen deposition was markedly decreased in $\mathrm{B}-M d r 2^{-/-}$ livers, as shown by reduced Sirius $\operatorname{Red}^{+}$fibrills and mRNA expression of fibrogenic genes (Col1a1, Col1a2; Fig. 5A,B). In agreement, $\alpha \mathrm{SMA}$ immunereactivity and liver $\operatorname{Pdg} f r \beta$ mRNA expression were reduced (Fig. 5C). This also correlated with a significant decrease of relative liver mass in $\mathrm{B}-\mathrm{Mdr} 2^{-/-}$ mice (Fig. 5D).

Transcript levels of liver $T g f b, T l r 4$, and $C c l 2$, mediators of hepatic fibrogenesis, were also markedly decreased in $\mathrm{B}-\mathrm{Mdr} 2^{--}$mice compared to controls (Fig. 5E). Furthermore, we observed that in B$M d r 2^{-/}$mice, the TNF $\alpha / \mathrm{NF}-\kappa \mathrm{B}$ axis was significantly 

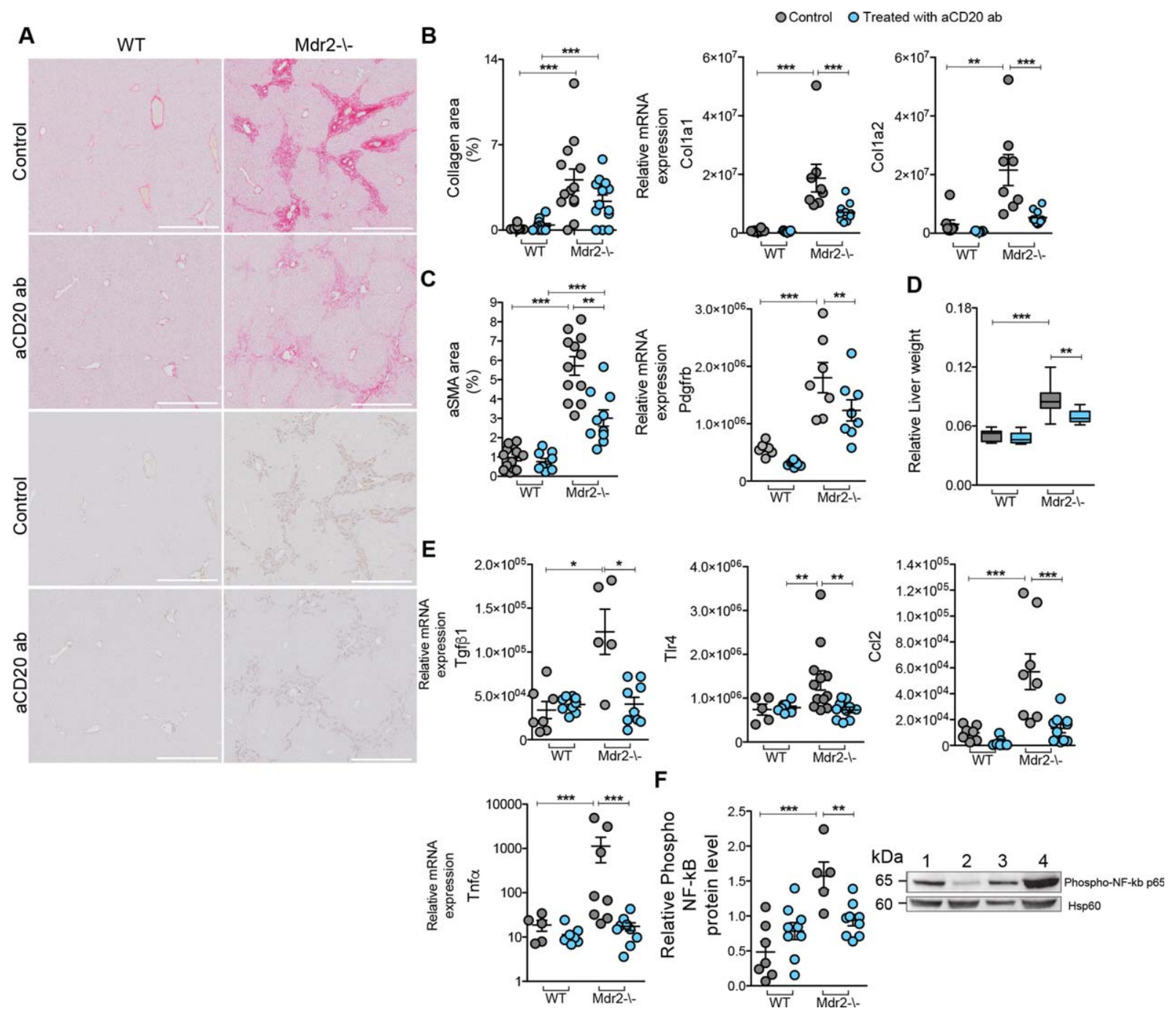

FIG. 5. B-lymphocyte depletion reduced HF in $M d r 2^{-/-}$mice. (A) Representative images from Sirius Red and $\alpha \mathrm{SMA}$ stainings on liver sections. (B) Quantification of Sirius Red-positive areas by laser scanning on liver sections and qRT-PCR analysis on expression of Colla1 and Col1a2. (C) Quantification of activated HSCs (aSMA) and relative expression level for Pdgfr- $\beta$ by qRT-PCR. (D) Relative liver weight is shown. (E) Quantitative analysis of fibrogenic markers: Tgf $\beta 1$, Tlr4, Ccl2, and Tnf $\alpha$ was performed by qRTPCR on total liver tissue. (F) Representative immunoblotting for phospho-NF- $\kappa \mathrm{B} / \mathrm{p} 65$ and Hsp60. Immunoblotting samples: $1=$ aCD20-wt; $2=$ wt; $3=$ aCD20 Mdr2 ${ }^{-1-} ; 4=M d r 2^{-1-}$. Data are represented as a mean \pm SEM. ${ }^{*} P<0.05 ;{ }^{* *} P<0.01$. Abbreviation: Hsp-60, heat shock protein 60 .

attenuated (Fig. 5E,F), demonstrating the mechanistic contributions of $\mathrm{B}$ cells in the inflammation of $M d r 2^{-1-}$ mice. Consistent with their decreased activation, the secretory phenotype of HSCs isolated from $\mathrm{B}-M d r 2^{-/}$mice was similar to that observed for senescent Dko cell cultures, with high production of IL $1 \alpha$, Cc12, and IL6 cytokines (Supporting Fig. S3D,E). To confirm the role of $\mathrm{B}$ cells in LF, we crossed the Bcell-deficient $\mu \mathrm{MT}$ mouse with the $\mathrm{Mdr}^{-/-}$mouse and analyzed the progenies. Their analysis at 7 months of age revealed significant amelioration of LF and inflammation (Supporting Fig. S5), further suggesting that $\mathrm{B}$ cells play a critical role in amplification of the fibrotic process of $M d r 2^{-/-}$mice, which also involved activation/regulation of the senescent program.

Interestingly, as reported for experimental models of $\mathrm{LF}$ induced in T-cell-deficient mice, ${ }^{(12)} \mathrm{LF}$ was not significantly affected by the CD4/CD8 T-cell depletion (Supporting Fig. S6A,B). Similar to $M d r 2^{-/}$ immune-competent mice, $\mathrm{T}-M d r 2^{-/-}$mice showed 


\section{oWT oMdr2-I- • Rag2-I-Mdr2-I- o uMT-Mdr2---}

A

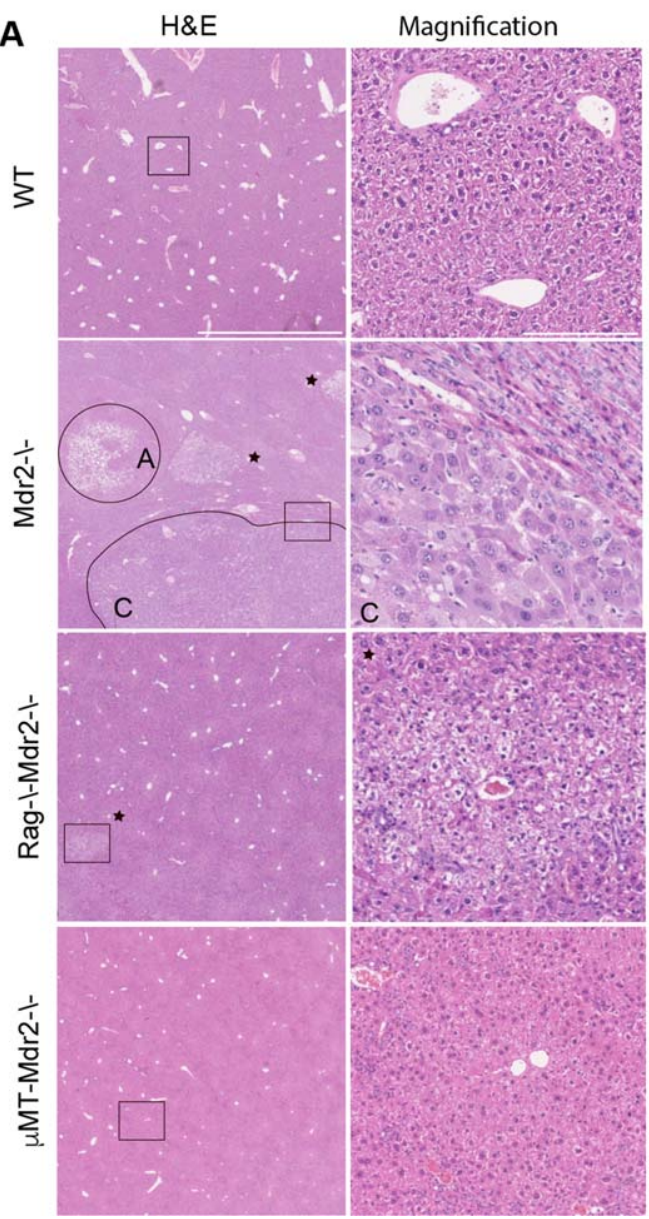

B

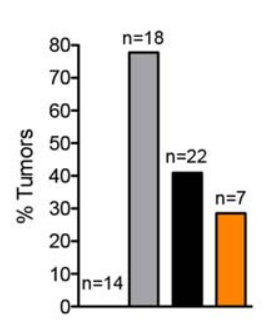

C

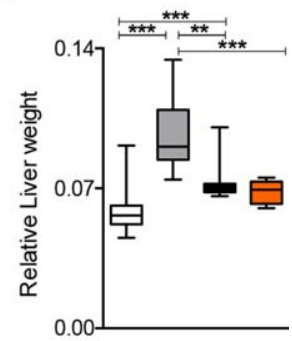

D

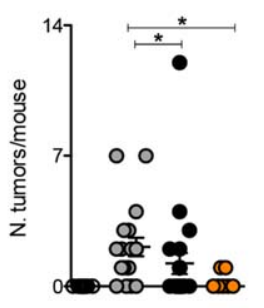

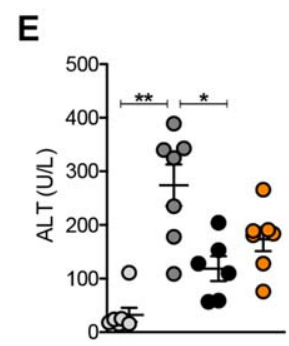

FIG. 6. Reduced tumor development in the absence of lymphocytes. (A) Representative images showing H\&E staining of liver sections from tumor-bearing $M d r 2^{-/-}$mice and age-matched Dko, $\mu \mathrm{MT}-M d r 2-/$, and wt mice. Scale bar $=2.5 \mathrm{~mm}$. Magnification scale bar $=250 \mu \mathrm{m}$. Star = foci of cellular alteration; $\mathrm{A}=$ hepatocellular adenoma; $\mathrm{C}=\mathrm{HCC}$ (H\&E staining). Quantification of tumor incidence (B), relative liver weight (C), relative tumor incidence for mouse, and total proliferative lesions (D) are shown. (E) Analysis of serum ALT in 16 -month-old mice. ${ }^{*} P<0.05$; ${ }^{*} P<0.01$. Abbreviation: H\&E, hematoxylin and eosin.

nearly intact collagen deposition, unaltered $\alpha$ SMAexpressing HSCs, and an up-regulated proinflammatory/fibrogenic tissue phenotype (Supporting Fig. S6C-G).

\section{TUMOR DEVELOPMENT IS MARKEDLY REDUCED IN $\operatorname{Rag} 2^{-/-} \mathrm{Mdr2}^{-/-} \mathrm{MICE}$}

Both accumulation of senescent cells and sustained inflammation could contribute to malignant transformation. ${ }^{(6,8,10,11)}$ Therefore, we analyzed tumorigenesis in Dko mice, in which inflammation-driven fibrosis is restrained by cellular senescence but senescence- surveillance is partially impaired. At 16 months of age, $80 \%$ of $M d r 2^{-/-}$mice developed visible nodules classified as HCC, whereas no age-matched wt mice presented with HCC (Fig. 6A,B). This finding in the $M d r 2^{-/}$mice coincided with strongly increased relative liver weight attributed to tumor burden (mean $0.09 \pm 0.01 \mathrm{SD}$ in $M d r 2^{-/-}$mice vs. $0.07 \pm 0.01$ in Dko mice vs. $0.05 \pm 0.01$ in wt; Fig. 6C). Of note, HCC development was considerably attenuated in Dko mice, with a 2-fold reduction in overall tumor frequency and a reduced number of macroscopically detected tumors for the single mouse (Fig. 6A-D). In addition, tumor-bearing Dko mice displayed a lower number of total proliferative lesions, including pretumoral foci of cellular alteration and tumors (Fig. 6D). 

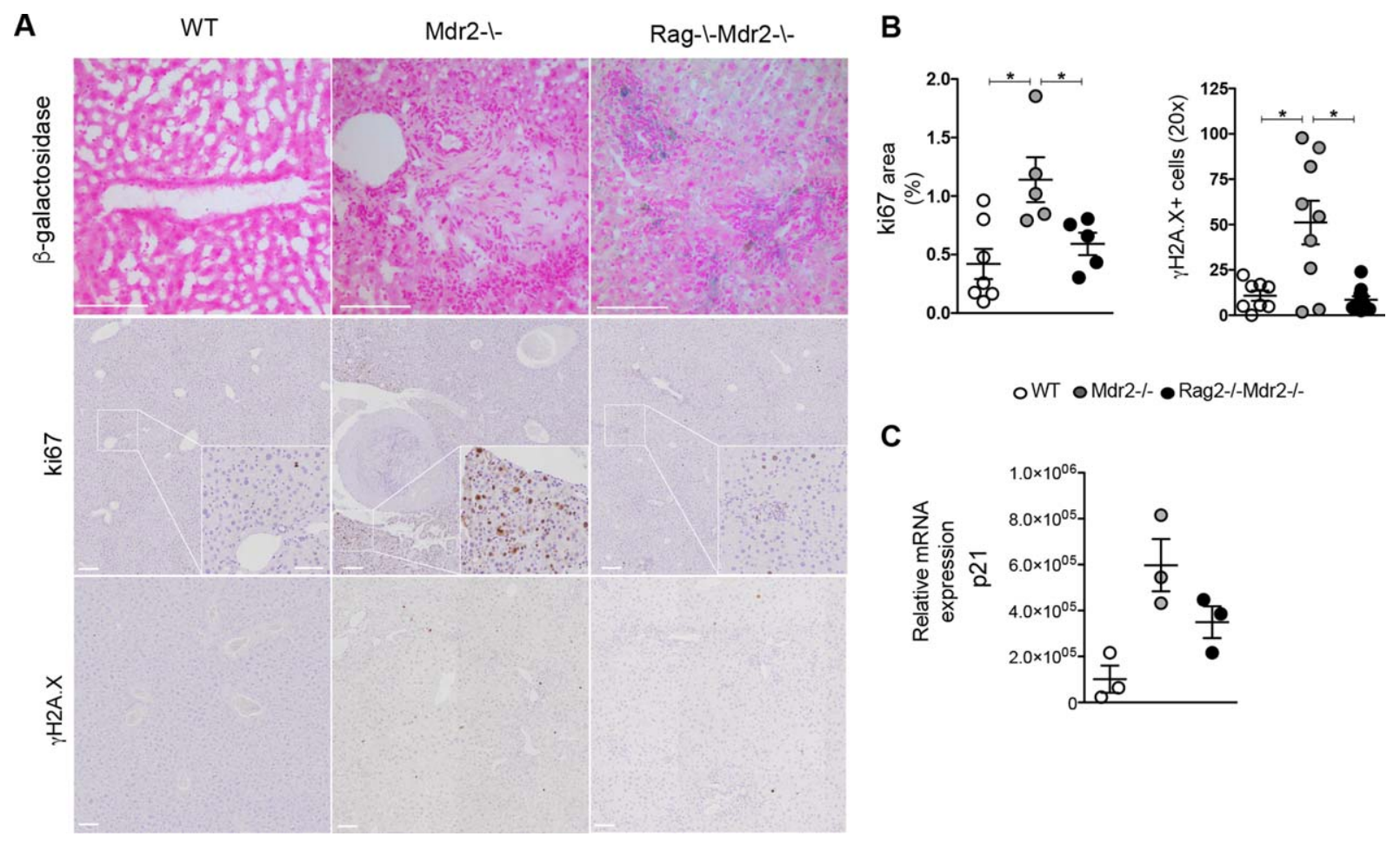

FIG. 7. Mechanisms of suppressed HCG in immunodeficient $M d r 2^{-/}$mice. (A) Liver sections from 16-month-old mice were processed for detection of $\beta$-gal activity (top) and stained for Ki-67 (middle) and for $\gamma$ H2A.X (bottom) markers. Scale bar $=200 \mu$ m; magnification scale bar $=67 \mu \mathrm{m}$. (B) Quantification of proliferating cells and foci of DNA damage in mutants and control livers are shown. (C) p21 expression was assessed by qRT-PCR in isolated hepatocytes from mutants and wt mice. Data are represented as a mean \pm SEM. ${ }^{*} P<0.05 ;{ }^{* *} P<0.01$.

Furthermore, Dko animals displayed a significantly reduced serum aminotransferase (alanine aminotransferase; ALT) level, indicative of milder liver damage (Fig. 6E).Importantly, analogous results were obtained for $\mu \mathrm{MT}-M d r 2^{-/}$mice at a similar age (Fig. $6 \mathrm{~A}-\mathrm{E}$ ).

Next, we evaluated whether cellular senescence could be a potential contributor to HCC arrest in Dko mice. At 16 months, SA- $\beta$-gal ${ }^{+}$cells persisted in liver of Dko mice, whereas $M d r 2^{-/-}$hepatic tissues were almost negative (Fig. 7A). Hepatocyte proliferation with damaged DNA is a key factor in the formation of HCC. ${ }^{(25)}$ As expected, hepatocyte proliferation was evident in $M d r 2^{-/-}$livers and associated with increased DNA double-strand breaks, as assessed by Ki-67 (1.14 $\pm 0.4 \%$ in $M d r 2^{-/-}$mice vs. $0.4 \pm 0.3 \%$ in wt controls) and $\gamma \mathrm{H} 2 \mathrm{~A} . \mathrm{X}$ staining $(51 \pm 36$ positive cells in $M d r 2^{-/-}$mice vs. $10 \pm 7$ in wt controls), respectively (Fig. 7A,B). On the contrary, in Dko mice, we observed reduced hepatocyte proliferation $(0.5 \pm$ $0.2 \%)$ and protection from DNA damage $(8.6 \pm 6.2$ positive cells; Fig. 7A,B). In the $M d r 2^{-1-}$ mouse, p21 promotes both liver regeneration and hepatocarcinogenesis (HCG). ${ }^{(26)}$ In agreement, higher p21 mRNA was detected in $M d r 2^{-/}$hepatocytes compared to controls, whereas its expression was down-regulated in Dko hepatocytes (Fig. 7C), confirming lymphocytes as a critical component linking inflammation and HCG, by sustaining DNA damage, cell proliferation, and neoplastic transformation.

\section{B CELLS ACCUMULATE IN POORLY DIFFERENTIATED HUMAN HCC}

Next, we sought to investigate whether the presence of B lymphocytes mirrors, in human HCC, the protumorigenic role shown in our mouse models. Thus, we analyzed a monoinstitutional cohort of 116 surgically resected $\mathrm{HCC}$ patients with $\mathrm{HCV}$ etiology. The amount of B lymphocytes was analyzed in tumoral and extratumoral tissues. B cells were classified as absent, 


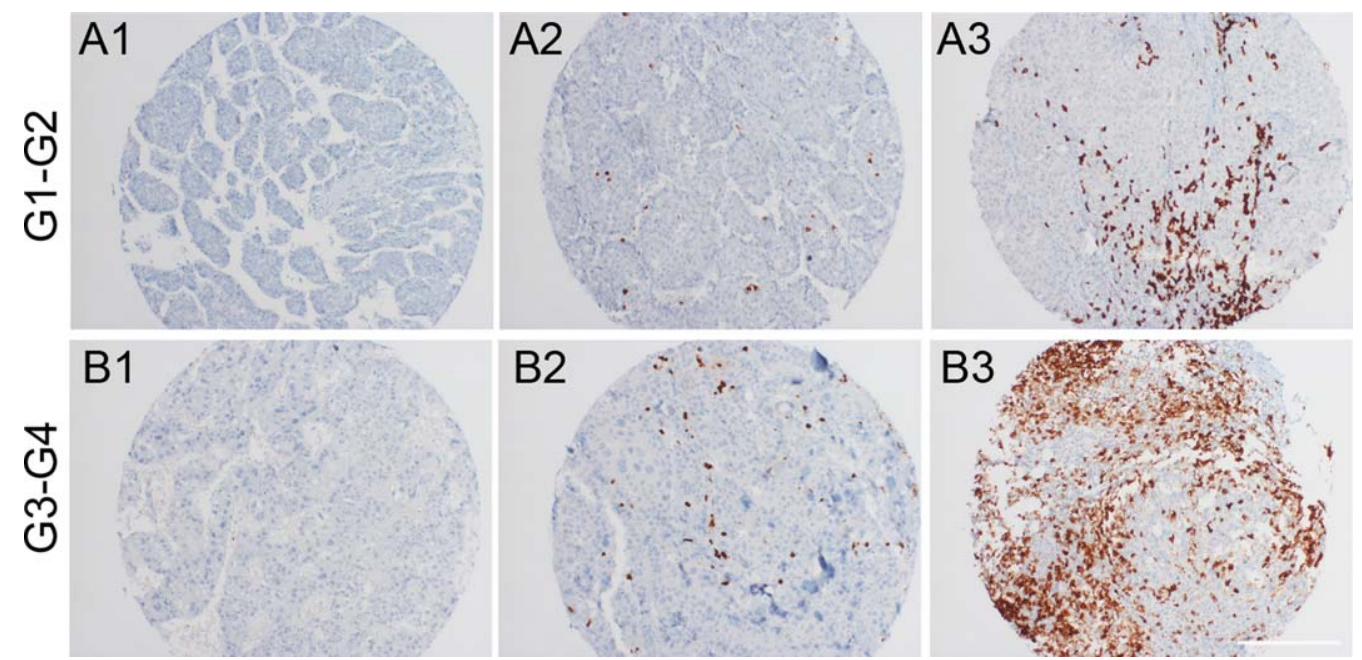

FIG. 8. Increased B infiltrates is a feature of poor differentiation in HCC patients. The upper part of the picture illustrates 3 cases of well-differentiated HCC showing a different amount of tumoral CD20 ${ }^{+}$B lymphocytes: They are absent in A1, ranging between $1 \%$ and $10 \%$ in $\mathrm{A} 2$ and $\geq 11 \%$ in A3. The lower part of the picture illustrates a similar distribution of B-cell lymphocytes in a series of poorly differentiated HCC. Scale bar $=250 \mu \mathrm{m}$.

$1 \%-10 \%$ or $\geq 11 \%$ in, respectively, $21 \%, 86 \%$, and $3 \%$ of HCC samples and in $2 \%, 86 \%$, and $12 \%$ of extralesional liver parenchyma. Next, we explored a possible correlation between tumoral/extratumoral B-cell infiltrate and clinical (overall and disease-free survival), pathological (histotype, grade, stage, and microscopic or macroscopic angioinvasion), and phenotypical features (p53, B-catenin, stem cell markers, and Ki-67 expression) of the series. Interestingly, a higher amount of B lymphocytes within HCC showed a significant correlation with poor differentiation (G1-G2 vs. G3G4: $2.3 \pm 2.0$ vs. $4.1 \pm 4.0 ; P=0.004)$ and with lower disease-free survival $(\mathrm{HR}=1.07 ; 95 \% \mathrm{CI}=$ 1.00-1.14; $P=0.05$; Fig. 8). By contrast, at this late HCC stage, the presence of B lymphocytes in extratumoral tissue did not show any statistical correlation.

\section{Discussion}

In this study, we addressed the impact of the adaptive immune system on the fibrogenic response that accompanies the development of HCC in $M d r 2^{-1-}$ mice. We show that activated liver lymphocytes amplify the fibrogenic response by secreting proinflammatory cytokines, including TNF $\alpha$. Ablation of adaptive immunity strongly suppressed HSC activation, promoting their transition to cellular senescence. Additionally, absence of liver lymphocytes led to a switch in the liver metabolic/oxidative state, resulting in skewed macrophage polarization toward an antiinflammatory restorative M2 phenotype. Notably, lack of lymphocytes markedly halted HCG, hindering $\mathrm{TNF} \alpha / \mathrm{NF}-\kappa \mathrm{B}$ pathway activation. Mechanistically, we found that $\mathrm{TNF} \alpha$-producing $\mathrm{CD} 20^{+} \mathrm{B}$ cells, but not $\mathrm{T}$ cells, limit senescence-mediated LF resolution, favoring $\mathrm{HCC}$ progression. These results indicate that B lymphocytes have a decisive role in cancer development following chronic liver injury.

Elements of both innate and adaptive immunity are pivotal in regulating inflammation-driven LF. ${ }^{(2)} \mathrm{How}^{-}$ ever, their role in its evolution to cancer is still to be unraveled. $M d r 2^{-1-}$ mice recapitulate key features of human liver tumorigenesis, including inflammatory environment, genomic instability, and fibrosis. ${ }^{(6,27,28)}$ It might therefore allow elucidating pathogenic components linking inflammation and HCG. In $M d r 2^{-1-}$ mice, chronic hepatitis preceding the neoplastic stage was accompanied by a substantial periportal B- and Tlymphocytic infiltration. Similarly, in chronic inflammatory human liver diseases, ${ }^{(29,30)}$ tertiary lymphoid follicles of $\mathrm{T}$ and $\mathrm{B}$ cells have a recognized implication for the disease pathogenesis. ${ }^{(31)}$ In line with this, LF and signs of liver injury were markedly reduced in the immunocompromised $\operatorname{Rag}^{-/-} M d r 2^{-/-}$mice.

The distinctive role of $\mathrm{B}$ and $\mathrm{T}$ cells in hepatic fibrogenesis has been dissected by administering lineage- 
specific depleting antibodies to $M d r 2^{-/}$mice, at the preneoplastic stage. Unlike T-Mdr2 $2^{-/}$mice, B$M d r 2^{-/-}$mice showed inhibition of fibrosis and accumulation of inactivated senescent HSCs similar to Dko animals, suggestive of a B-cell autonomous function. Anti-CD20 mAb treatment might halt several pathways through which B lymphocytes sustain HSC activation and ECM deposition. Our data indicate that hepatic B cells from fibrotic mice stimulate collagen production by direct secretion of profibrotic cytokines, such as TNF $\alpha$ and IL6. Moreover, B cells act to amplify proinflammatory circuits in effector immune cells, especially T cells. Additionally, B cells might influence macrophage polarization through an Fcy receptor-dependent signaling, ${ }^{(32)}$ directly stimulate fibroblasts, or inhibit metalloproteinase activity by antibody secretion. ${ }^{(33)}$ Overall, B-cell depletion primarily affects fibrosis by causing activated HSCs to convert into a senescent state.

Suppression of the immune system is commonly regarded as a risk factor for the development of de novo malignancies in patients, likely related to reduced immune surveillance and increased susceptibility to infections. ${ }^{(34,35)}$ Remarkably, tumor development was profoundly suppressed in Dko mice. Although the role of $\mathrm{TNF} \alpha$ in HCG remains controversial, ${ }^{(36)}$ in $M d r 2^{-/-}$mice, activation of the TNF $\alpha / \mathrm{NF}-\kappa \mathrm{B}$ pathway is responsible for tumor development, whereas neutralizing $\mathrm{TNF} \alpha$ antibody inhibits $\mathrm{NF}-\kappa \mathrm{B}$ activation and HCC development. ${ }^{(6)}$ Thus, the observed inhibition of the TNF $\alpha / \mathrm{NF}-\kappa \mathrm{B}$ axis is most likely responsible for the reduced carcinogenesis in the absence of $\mathrm{B}$ cells. Interestingly, serum ALT levels were significantly reduced in immunodeficient mice, emphasizing the link between liver inflammation and HCG. Likewise, in patients with hepatitis-associated cirrhosis, a direct correlation has been described between serum ALT, HCC recurrence rate, and kinetics. ${ }^{(37)}$

One limitation of our study is that we have only utilized one liver cancer mouse model. In this regard, it is noteworthy that a potential role for B cells in fibrosis has been previously proposed in mice treated with $\mathrm{CCl}_{4}{ }^{(12)}$ However, although it would be interesting to recapitulate our findings in other inflammation-driven models of $\mathrm{HCC},{ }^{(7,38)}$ different etiological settings might determine different immune responses, influencing the progression to $\mathrm{HCC}$ in a disease-specific context.

Strikingly, in Dko mice, HCC development was considerably attenuated, despite the important accumulation of senescent cells. The senescence response is widely recognized as a potent tumor-suppressive mechanism, but also a promoter of cancer initiation, by virtue of SASP-derived factors, a source of growth factors for tumor cells. ${ }^{(39)}$ In accord, clearance of senescent cells is an important mechanism of tumor surveillance in the liver cancer model and adaptive immune cells are involved in this process. ${ }^{(10,40)}$ Based on our results, it can be speculated that the senescencedriven inflammation have per se a dispensable role in neoplastic transformation, whereas HSC inactivation significantly limits the evolution of fibrosis. Moreover, lymphocyte-mediated inflammation is required for accumulation of DNA double-strand breaks in preneoplastic hepatocytes of $M d r 2^{-/}$mice, suggesting that B cells act by orchestrating the inflammatory and metabolic/oxidative environment that is a prerequisite for cancer development. Increasing evidence supports the role of B lymphocytes in tumor progression. ${ }^{41-43)}$ Our data in human HCC highlight infiltrating B cells as a prognostic tool to classify distinct clinical behaviors, identifying also B-cell responses as a possible target of immunotherapeutic strategies. In this regard, induction of senescence in tumor cells by chemotherapy or radiation is now becoming an emergent antitumoral approach. ${ }^{(44)}$ In our system, cellular senescence accumulates in the preneoplastic stage of Dko mice, limiting LF without promoting neoplastic transformation at later stage. It is tempting to speculate that in chronic disease, therapy-induced senescence (TIS) may be crucial to dampen fibrosis, extending the latency of HCC. This aspect is even more relevant for patients affected by cirrhosis for which liver transplantation is the only effective therapy. ${ }^{(45)}$ To translate our findings in clinical medicine, B-cell targeting may be an effective therapeutic strategy of TIS.

Acknowledgments: We thank Dr. Elena Fontana and Dr. Chiara Novello for technical assistance and the Clinical Chemistry \& Hematology Murine Laboratory at IRCCS S. Raffaele Scientific Institute for ALT analysis.

\section{REFERENCES}

1) Forner A, Llovet JM, Bruix J. Hepatocellular carcinoma. Lancet 2012;379:1245-1255.

2) Nakagawa $H$, Maeda S. Inflammation- and stress-related signaling pathways in hepatocarcinogenesis. World J Gastroenterol 2012;18:4071-4081.

3) Prieto J, Melero I, Sangro B. Immunological landscape and immunotherapy of hepatocellular carcinoma. Nat Rev Gastroenterol Hepatol 2015;12:681-700. 
4) Sica A, Invernizzi P, Mantovani A. Macrophage plasticity and polarization in liver homeostasis and pathology. Hepatology 2014;59:2034-2042.

5) Schneider C, Teufel A, Yevsa T, Staib F, Hohmeyer A, Walenda $G$, et al. Adaptive immunity suppresses formation and progression of diethylnitrosamine-induced liver cancer. Gut 2012;61:1733-1743.

6) Pikarsky E, Porat RM, Stein I, Abramovitch R, Amit S, Kasem $\mathrm{S}$, et al. NF-kappaB functions as a tumour promoter in inflammation-associated cancer. Nature 2004;431:461-466.

7) Endig J, Buitrago-Molina LE, Marhenke S, Reisinger F, Saborowski A, Schutt J, et al. Dual role of the adaptive immune system in liver injury and hepatocellular carcinoma development. Cancer Cell 2016;30:308-323.

8) Wolf MJ, Adili A, Piotrowitz K, Abdullah Z, Boege Y, Stemmer $\mathrm{K}$, et al. Metabolic activation of intrahepatic CD8 $+\mathrm{T}$ cells and NKT cells causes nonalcoholic steatohepatitis and liver cancer via cross-talk with hepatocytes. Cancer Cell 2014;26:549-564.

9) Braumuller H, Wieder T, Brenner E, Assmann S, Hahn M, Alkhaled M, et al. T-helper-1-cell cytokines drive cancer into senescence. Nature 2013;494:361-365.

10) Kang TW, Yevsa T, Woller N, Hoenicke L, Wuestefeld T, Dauch D, et al. Senescence surveillance of pre-malignant hepatocytes limits liver cancer development. Nature 2011;479:547-551.

11) Ma C, Kesarwala AH, Eggert T, Medina-Echeverz J, Kleiner $\mathrm{DE}$, Jin $\mathrm{P}$, et al. NAFLD causes selective CD4(+) T lymphocyte loss and promotes hepatocarcinogenesis. Nature 2016;531: 253-257.

12) Novobrantseva TI, Majeau GR, Amatucci A, Kogan S, Brenner I, Casola S, et al. Attenuated liver fibrosis in the absence of B cells. J Clin Invest 2005;115:3072-3082.

13) Mauad TH, van Nieuwkerk CM, Dingemans KP, Smit JJ, Schinkel AH, Notenboom RG, et al. Mice with homozygous disruption of the mdr2 P-glycoprotein gene. A novel animal model for studies of nonsuppurative inflammatory cholangitis and hepatocarcinogenesis. Am J Pathol 1994;145:1237-1245.

14) Fickert P, Fuchsbichler A, Wagner M, Zollner G, Kaser A, Tilg $\mathrm{H}$, et al. Regurgitation of bile acids from leaky bile ducts causes sclerosing cholangitis in Mdr2 (Abcb4) knockout mice. Gastroenterology 2004;127:261-274.

15) Fan Y, Arechederra M, Richelme S, Daian F, Novello C, Calderaro J, et al. A phosphokinome-based screen uncovers new drug synergies for cancer driven by liver-specific gain of nononcogenic RTKs. Hepatology 2017;66:1644-1661.

16) Fickert P, Pollheimer MJ, Beuers U, Lackner C, Hirschfield G, Housset $\mathrm{C}$, et al. Characterization of animal models for primary sclerosing cholangitis (PSC). J Hepatol 2014;60:1290-1303.

17) Shinkai Y, Rathbun G, Lam KP, Oltz EM, Stewart V, Mendelsohn M, et al. RAG-2-deficient mice lack mature lymphocytes owing to inability to initiate $\mathrm{V}(\mathrm{D}) \mathrm{J}$ rearrangement. Cell 1992;68:855-867.

18) Seki E, De Minicis S, Osterreicher CH, Kluwe J, Osawa Y, Brenner DA, Schwabe RF. TLR4 enhances TGF-beta signaling and hepatic fibrosis. Nat Med 2007;13:1324-1332.

19) Stechmiller JK, Childress B, Cowan L. Arginine supplementation and wound healing. Nutr Clin Pract 2005;20:52-61.

20) Rath M, Muller I, Kropf P, Closs EI, Munder M. Metabolism via arginase or nitric oxide synthase: two competing arginine pathways in macrophages. Front Immunol 2014;5:532.

21) Krizhanovsky V, Yon M, Dickins RA, Hearn S, Simon J, Miething C, et al. Senescence of activated stellate cells limits liver fibrosis. Cell 2008;134:657-667.

22) Kim KH, Chen CC, Monzon RI, Lau LF. Matricellular protein $\mathrm{CCN} 1$ promotes regression of liver fibrosis through induction of cellular senescence in hepatic myofibroblasts. Mol Cell Biol 2013;33:2078-2090.

23) Lau LF. CCN1/CYR61: the very model of a modern matricellular protein. Cell Mol Life Sci 2011;68:3149-3163.

24) Giannandrea M, Parks WC. Diverse functions of matrix metalloproteinases during fibrosis. Dis Model Mech 2014;7:193203.

25) Montalto G, Cervello M, Giannitrapani L, Dantona F, Terranova A, Castagnetta LA. Epidemiology, risk factors, and natural history of hepatocellular carcinoma. Ann N Y Acad Sci 2002;963:13-20.

26) Marhenke S, Buitrago-Molina LE, Endig J, Orlik J, Schweitzer $\mathrm{N}$, Klett $\mathrm{S}$, et al. p21 promotes sustained liver regeneration and hepatocarcinogenesis in chronic cholestatic liver injury. Gut 2014;63:1501-1512.

27) Barash H, Gross E, Edrei Y, Pappo O, Spira G, Vlodavsky I, et al. Functional magnetic resonance imaging monitoring of pathological changes in rodent livers during hyperoxia and hypercapnia. Hepatology 2008;48:1232-1241.

28) Katzenellenbogen $M$, Pappo O, Barash $H$, Klopstock $N$, Mizrahi L, Olam D, et al. Multiple adaptive mechanisms to chronic liver disease revealed at early stages of liver carcinogenesis in the Mdr2-knockout mice. Cancer Res 2006;66:4001-4010.

29) Murakami J, Shimizu Y, Kashii $Y$, Kato T, Minemura M, Okada $\mathrm{K}$, et al. Functional B-cell response in intrahepatic lymphoid follicles in chronic hepatitis C. Hepatology 1999;30:143-150.

30) Grant AJ, Lalor PF, Hubscher SG, Briskin M, Adams DH. MAdCAM-1 expressed in chronic inflammatory liver disease supports mucosal lymphocyte adhesion to hepatic endothelium (MAdCAM-1 in chronic inflammatory liver disease). HEPATOLOGY 2001;33:1065-1072.

31) Pitzalis C, Jones GW, Bombardieri M, Jones SA. Ectopic lymphoid-like structures in infection, cancer and autoimmunity. Nat Rev Immunol 2014;14:447-462.

32) Andreu P, Johansson M, Affara NI, Pucci F, Tan T, Junankar $\mathrm{S}$, et al. FcRgamma activation regulates inflammation-associated squamous carcinogenesis. Cancer Cell 2010;17:121-134.

33) Sato S, Hayakawa I, Hasegawa M, Fujimoto M, Takehara K. Function blocking autoantibodies against matrix metalloproteinase- 1 in patients with systemic sclerosis. J Invest Dermatol 2003;120:542547.

34) Kumar A, Le DT. Hepatocellular carcinoma regression after cessation of immunosuppressive therapy. J Clin Oncol 2016;34: e90-e92.

35) Schrem H, Kurok M, Kaltenborn A, Vogel A, Walter U, Zachau L, et al. Incidence and long-term risk of de novo malignancies after liver transplantation with implications for prevention and detection. Liver Transpl 2013;19:1252-1261.

36) Jang MK, Kim HS, Chung YH. Clinical aspects of tumor necrosis factor-alpha signaling in hepatocellular carcinoma. Curr Pharm Des 2014;20:2799-2808.

37) Tarao K, Rino Y, Ohkawa S, Shimizu A, Tamai S, Miyakawa $\mathrm{K}$, et al. Association between high serum alanine aminotransferase levels and more rapid development and higher rate of incidence of hepatocellular carcinoma in patients with hepatitis C virus-associated cirrhosis. Cancer 1999;86:589-595.

38) Haybaeck J, Zeller N, Wolf MJ, Weber A, Wagner U, Kurrer $\mathrm{MO}$, et al. A lymphotoxin-driven pathway to hepatocellular carcinoma. Cancer Cell 2009;16:295-308.

39) Campisi J. Aging, cellular senescence, and cancer. Annu Rev Physiol 2013;75:685-705.

40) Xue W, Zender L, Miething C, Dickins RA, Hernando E, Krizhanovsky V, et al. Senescence and tumour clearance is 
triggered by $\mathrm{p} 53$ restoration in murine liver carcinomas. Nature 2007;445:656-660.

41) de Visser KE, Korets LV, Coussens LM. De novo carcinogenesis promoted by chronic inflammation is B lymphocyte dependent. Cancer Cell 2005;7:411-423.

42) Affara NI, Ruffell B, Medler TR, Gunderson AJ, Johansson M, Bornstein S, et al. B cells regulate macrophage phenotype and response to chemotherapy in squamous carcinomas. Cancer Cell 2014;25:809-821.

43) Shalapour S, Font-Burgada J, Di Caro G, Zhong Z, Sanchez-Lopez E, Dhar D, et al. Immunosuppressive plasma cells impede T-celldependent immunogenic chemotherapy. Nature 2015;521:94-98.
44) Ewald JA, Desotelle JA, Wilding G, Jarrard DF. Therapy-induced senescence in cancer. J Natl Cancer Inst 2010;102:1536-1546.

45) Bataller R, Brenner DA. Liver fibrosis. J Clin Invest 2005;115: 209-218.

Author names in bold designate shared co-first authorship.

\section{Supporting Information}

Additional Supporting Information may be found at onlinelibrary.wiley.com/doi/10.1002/hep.29636/suppinfo. 